\title{
Repression of Inducible Tartrate Dehydratases in Pseudomonas Strains
}

\author{
By R. F. ROSENBERGER AND M. SHILO \\ Laboratory of Microbiological Chemistry, Department of Biochemistry, \\ Hebrew University-Hadassah Medical School, Jerusalem, Israel
}

(Received 1 October 1962)

\section{SUMMARY}

The effect of various growth substrates on the synthesis of three inducible enzymes, the stereo-specific tartrate dehydratases, has been followed in strains of Pseudomonas. Four organic acids (succinate, malate, acetate, meso-tartrate) inhibited induction of some or of all of the tartrate dehydratases, while three (pyruvate, $l$-tartrate, and $d$-tartrate) did not inhibit. Whenever inhibition occurred, synthesis of $d$ - and $l$-tartrate dehydratase was repressed much more strongly than synthesis of meso-tartrate dehydratase. Pre-induction of the bacteria did not prevent subsequent repression and a degree of correlation was found between the growth rate supported by substrates and the extent of repression. The significance of the different degrees of repression given by substrates feeding into closely related sites of the Krebs cycle and of the differences in repression exerted on enzymes acting on closely related compounds is discussed.

\section{INTRODUCTION}

Several structurally unrelated metabolizable substrates have been shown to inhibit the synthesis of certain enzymes in bacteria (Monod, 1942; Mandelstam, 1961; Magasanik, 1961). To explain the inhibition, it has been suggested that these substrates give rise to metabolic intermediates which act as enzyme repressors. Thus the effect, which has been known for many years as diauxie or the 'glucose effect', has recently been termed catabolite repression (Mandelstam, 1961; Magasanik, 1961). While little is known about the nature or the specificity of the substances responsible for catabolite repression (Engelsberg, Watson \& Hoffe, 1961 ; Magasanik, 1961; Mandelstam, 1962), studies on the relation between substrate metabolism and concentration of constitutive enzymes in Escherichia coli and yeasts have indicated that compounds other than the specific repressors considered responsible for the induction phenomenon are involved (Brown \& Monod, 1961; Mandelstam, 1962; McQuillan \& Halvorson, 1962).

In the experiments to be reported, aspects of catabolite repression have been studied in strains of Pseudomonas which metabolize inductively two or all three of the optical isomers of tartaric acid. Induction to tartrate utilization in these strains involves the synthesis of dehydratases which catalyse the conversion of tartrate isomers to oxaloacetate. Three tartrate dehydratases, each specific for one of the optical isomers, are known; these are induced only by their particular substrates (Shilo, 1957; Shilo \& Stanier, 1957). Catabolite repression of tartrate dehydratase synthesis by organic acids has been reported (Rosenberger \& Shilo, 1961). In the 
present work attempts have been made to study the specificity of repression against the three dehydratases and to determine, by the use of substrates which enter metabolism at identical or closely related points of the Krebs cycle, which metabolic steps are critical for the accumulation of enzyme repressors. Substrates such as the three tartrate isomers, succinate, malate, acetate and pyruvate share all or nearly all of their catabolic pathways and differences in the degree of repression should be traceable to differences in the rates of the small number of metabolic steps not common to each or to specific unshared intermediates.

\section{METHODS}

Organisms. The strains of Pseudomonas used were described by Shilo \& Stanier (1957).

Media and growth conditions. The basal medium used contained per 1 . distilled $\mathrm{H}_{2} \mathrm{O}:\left(\mathrm{NH}_{4}\right)_{2} \mathrm{SO}_{4}, 1$ g.; $\mathrm{KH}_{2} \mathrm{PO}_{4}, 1.5 \mathrm{~g}$.; $\mathrm{Na}_{2} \mathrm{HPO}_{4}, 0.25$ g.; $\mathrm{MgSO}_{4} .7 \mathrm{H}_{2} \mathrm{O}, 50 \mathrm{mg}$.; $\left(\mathrm{NH}_{4}\right)_{2} \mathrm{SO}_{4} \cdot \mathrm{FeSO}_{4} \cdot 6 \mathrm{H}_{2} \mathrm{O}, 5 \mathrm{mg}$.; Yeast extract (Difco), $25 \mathrm{mg}$; $\mathrm{pH} 6$. Carbon sources were added to a final concentration of $0.3 \%(w / v)$ or as indicated in the text. Carbon source and basal medium were sterilized together by autoclaving $\left(20\right.$ min. at $\left.121^{\circ}\right)$ except in the case of sodium pyruvate which was sterilized by filtration. Cultures were grown in Erlenmeyer flasks on a rotary shaker at $30^{\circ}$.

Enzyme assays. For $d$-tartrate dehydratase estimations organisms were washed once in $50 \mathrm{~mm}$-tris (2-amino-2 hydroxymethylpropane-1,3-diol) buffer ( $\mathrm{pH} \mathrm{8.7),}$ re-suspended in the same buffer and lysed by the addition of $4 \mu$ mole ethylenediaminetetra-acetic acid (EDTA) and $20 \mu \mathrm{g}$. lysozyme/ml. (Repaske, 1958). The lysates were incubated for $10 \mathrm{~min}$. at $30^{\circ}$ with $12.5 \mathrm{~mm}-d$-tartrate, $4 \mathrm{~mm}$-EDTA and $50 \mathrm{~mm}$-tris buffer ( $\mathrm{pH} \mathrm{8 \cdot 7)}$ ). In the presence of dehydratase and EDTA, oxaloacetate accumulated without further enzymic breakdown (Shilo, 1957). The reaction was stopped by the addition of trichloroacetic acid, and, after centrifugation to remove precipitated proteins, the keto acids formed were estimated by the method of Friedman \& Haugen (1943).

Meso-tartrate dehydratase was assayed as above, but with the substitution of 20 mm-phosphate buffer (pH 7-2) for tris buffer and 12.5 mM-meso-tartrate for $d$-tartrate. For both enzymes under the above conditions, keto-acid accumulation proceeded at a linear rate for at least $15 \mathrm{~min}$., and was proportional to the enzyme concentration. One dehydratase unit has been taken as the amount forming $1 \mu$ mole keto acid/hour.

Oxygen uptake with various substrates. Ability to oxidize substrates with or without lag was measured by the conventional Warburg technique at $30^{\circ}$.

Estimation of bacterial dry weight and protein. Bacterial dry weights were determined by turbidity measurements in a Klett-Summerson colorimeter by comparison with a calibration curve. Protein was estimated by the method of Lowry, et al. (1951) with bovine serum albumin as standard.

Estimation of d-tartrate was by the method of Matchett et al. (1944). When the kinetics of $d$-tartrate utilization by washed suspensions were followed, samples were boiled for 2 min. to stop further breakdown, solids removed by centrifugation and assays performed on the supernatant fluid. 


\section{RESULTS}

\section{Repression of tartrate dehydratase synthesis by organic acids}

Organisms were grown with the substrate under test as sole source of carbon and energy and, when the logarithmic phase of growth was reached, one of the tartrate isomers was added as inducer. Cultures had a density of $0 \cdot 1-0 \cdot 2 \mathrm{mg}$. bacterial dry weight $/ \mathrm{ml}$. at the time of inducer addition and induction was followed for about two generations. When induction occurred under the above conditions, plots of the amounts of $d$ - or meso-tartrate dehydratase formed against total bacterial protein had the form of a straight line. The slope of this line, the differential rate of synthesis, was used to compare the rates of inductive enzyme formation. As no quantitative assay methods for $l$-tartrate dehydratase are available, adaptation to $l$-tartrate utilization was determined manometrically. Organisms were harvested approximately two generations after inducer addition, and their ability to oxidize $l$-tartrate without lag determined.

Table 1. Rate of d-tartrate dehydratase synthesis on inducer addition to Pseudomonas strains growing with various organic acids

Differential rate of enzyme synthesis* during growth on following substrates plus inducer $\dagger$

\begin{tabular}{|c|c|c|c|c|c|c|c|}
\hline \multirow{2}{*}{$\begin{array}{c}\text { Pseudo- } \\
\text { monas } \\
\text { strain }\end{array}$} & \\
\hline & $d$-tartrate & $l$-tartrate & $\begin{array}{c}\text { meso- } \\
\text { tartrate }\end{array}$ & Succinate & $d l$-malate & Acetate & Pyruvate \\
\hline MD9 & $28 \cdot 3$ & $25 \cdot 9$ & $<\mathbf{2}$ & $<\mathbf{2}$ & $<2$ & n.g. & $42 \cdot 7$ \\
\hline LML & $26 \cdot 9$ & 32.2 & $<2$ & $<2$ & $<2$ & $<2$ & 35.1 \\
\hline MD & $32 \cdot 6$ & n.g. & $<2$ & $<2$ & $<2$ & $<2$ & $41 \cdot 7$ \\
\hline 12 & 16.5 & $11 \cdot 6$ & n.g. & $<\mathbf{2}$ & $<\mathbf{2}$ & $<2$ & $6 \cdot 4$ \\
\hline
\end{tabular}

* $d$-tartrate dehydratase units formed/mg. total protein synthesized; $\dagger 0.3 \%(w / v)$ substrate $+0 \cdot 1 \%(w / v)$ inducer; n.g., no growth with substrate as sole carbon source.

Table 2. Rate of meso-tartrate dehydratase synthesis on inducer addition to Pseudomonas strains growing with various organic acids

Differential rate of enzyme synthesis* during growth on following

$\begin{array}{lcccccc}\begin{array}{c}\text { Pseudo- } \\ \text { monas } \\ \text { strain }\end{array} & \begin{array}{c}\text { meso- } \\ \text { tartrate }\end{array} & d \text {-tartrate } & l \text {-tartrate } & \text { succinate } & d l \text {-malate } & \text { acetate } \\ \text { MD9 } & 147 & 81 & 117 & 19 & 29 & \text { n.g. } \\ \text { MD } & 114 & 121 & \text { n.g. } & 54 & 53 & 46 \\ \text { LML } & 83 & 196 & 135 & 17 & 74 & 28\end{array}$

* meso-tartrate dehydratase units formed/mg. total protein synthesized; $\dagger 0.3 \%$ (w/v) substrate $+0 \cdot 1 \%(w / v)$ inducer; $n . g .=$ no growth with substrate as sole carbon source.

The results obtained with four strains and seven organic acids are summarized in Tables 1, 2 and 3. Induction of $d$ - or $l$-tartrate dehydratase was completely inhibited by intermediates of the Krebs cycle and by meso-tartrate. With both these dehydratases, pyruvate and the non-inducing optically active tartrate isomer allowed synthesis to proceed at rates comparable to those with inducer 
alone. Meso-tartrate dehydratase synthesis was not inhibited by the other tartrate isomers and was in no case completely repressed. Pyruvate stood out from the other Krebs cycle intermediates tested, since in its presence synthesis of any of the three inducible dehydratases proceeded at rates equal to those with inducer alone.

Table 3. Induction to 1-tartrate oxidation after inducer addition to Pseudomonas strains growing with various organic acids

\begin{tabular}{|c|c|c|c|c|}
\hline \multirow{2}{*}{$\begin{array}{c}\text { Pseudomonas } \\
\text { strain }\end{array}$} & \multicolumn{4}{|c|}{$\begin{array}{c}\mathrm{O}_{2} \text { uptake }(0-20 \text { min.; substrate } l \text {-tartrate) of washed } \\
\text { organisms harvested after growth on following } \\
\text { substrates plus inducer } \dagger\end{array}$} \\
\hline & $d$-tartrate & meso-tartrate & succinate & pyruvate \\
\hline MD9 & 76 & 4 & 16 & 70 \\
\hline LML & 63 & 10 & 15 & 61 \\
\hline 12 & 80 & n.g. & 16 & 64 \\
\hline
\end{tabular}

* $\mu \mathrm{l} . \mathrm{O}_{2} / \mathrm{mg}$. dry wt., bacteria corrected for endogenous respiration; $† 0.3 \%(w / v)$ substrate + $0 \cdot 1(w / v)$ inducer; n.g. = no. growth of strain with substrate as sole carbon source.

Table 4. Meso-tartrate dehydratase synthesis in washed suspensions of Pseudomonas strain MD 9

\begin{tabular}{|c|c|c|}
\hline Time & $\begin{array}{l}\text { Treatment and } \\
\text { substrates added }\end{array}$ & $\begin{array}{l}\text { Rate of meso-tartrate } \\
\text { dehydratase syn- } \\
\text { thesis (units/mg. } \\
\text { protein/hr.) in } \\
\text { washed organisms* } \\
\text { previously grown } \\
\text { on succinate }\end{array}$ \\
\hline 0-30 min. & succinate (20 mu) & - \\
\hline 30-120 min. & $\begin{array}{l}\text { meso-tartrate }(6.6 \mathrm{mM}) \\
\text { succinate }(20 \mathrm{mM})\end{array}$ & $3 \cdot 4$ \\
\hline 120-180 min. & $\begin{array}{l}\text { Organisms centrifuged, } \\
\text { re-suspended in buffer } \\
\text { +6.6 mM meso-tartrate }\end{array}$ & $10 \cdot 6$ \\
\hline
\end{tabular}

* Organisms washed once in $22 \mathrm{~mm}$ phosphate buffer (pH 7·2), resuspended in same buffer.

Repression of meso-tartrate dehydratase synthesis in washed suspensions

Synthesis of meso-tartrate dehydratase was inhibited to a rather variable extent during growth on Krebs cycle intermediates, but was never completely repressed (Table 2). Since catabolite repression of certain enzymes has been shown to be more severe in washed suspensions than in growing cultures (Mandelstam, 1961), the effect of succinate on induction by meso-tartrate in washed suspensions was examined (Table 4). While succinate decreased the rate of dehydratase formation, induction did take place. Meso-tartrate dehydratase thus appeared to be more resistant to repression by metabolic intermediates than most other catabolic enzymes (Magasanik, 1961).

\section{Effect of meso-tartrate on induction by gluconate}

As growth on meso-tartrate inhibited induction of the $d$ - or $l$-tartrate dehydratases, it seemed of interest to determine its effect on a third inducible system. 
Organisms of Pseudomonas strain MD9 grown on meso-tartrate oxidized gluconate only after a pronounced lag, showing the inducible nature of this system. Addition of gluconate to organisms growing on meso-tartrate yielded organisms fully induced to gluconate oxidation. The tartrate isomer thus did not repress induction by gluconate.

\section{Influence of inducer and substrate concentrations on repression}

Pseudomonas strain $\mathrm{md}_{9}$ was grown on various concentrations of meso- or $d$-tartrate and graded concentrations of $d$ - or meso-tartrate were added as inducer. With meso-tartrate as substrate and the $d$-tartrate as inducer, the highest inducer/ substrate ratio tried $(6: 1)$ did not induce. In the reverse case, with $d$-tartrate as substrate and meso-tartrate as inducer, the lowest inducer/substrate ratio tried (1:6) yielded induced organisms (Fig. 1).

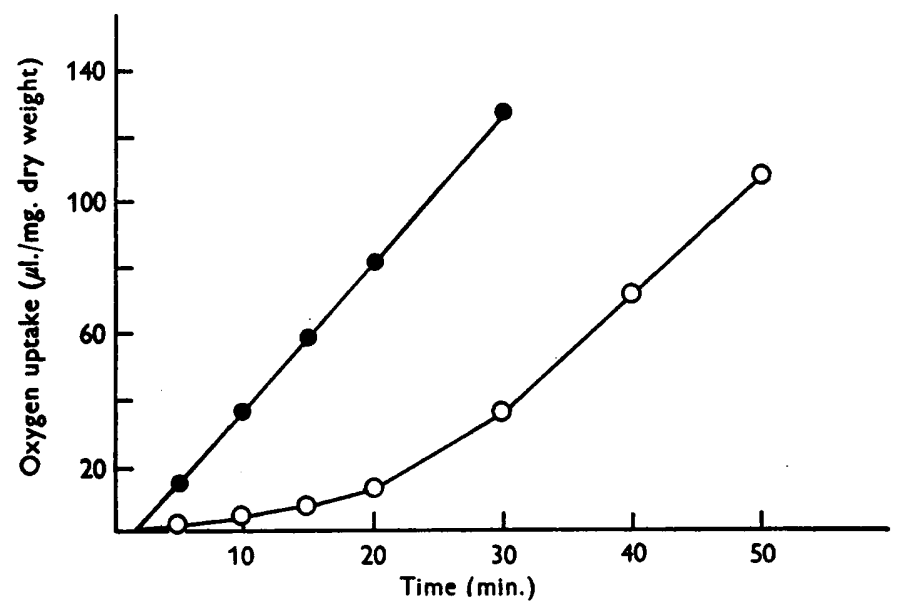

Fig. 1. Effect of differing ratios of inducer to substrate on induction in strain $\mathrm{md}_{0}$. Cells were grown on $3.8 \times 10^{-3} \mathrm{M}$ meso-tartrate with subsequent addition of $2 \times 10^{-2} \mathrm{M} d$-tartrate (O-O) or on $2 \times 10^{-8} \mathrm{M} d$-tartrate with subsequent addition of $8.3 \times 10^{-8} \mathrm{M}$ mesotartrate (-) . Approximately 2 generations after inducer addition cells were harvested and ability to oxidize meso- or $d$-tartrate without lag examined by the conventional Warburg technique.

\section{Effect of organic acids on inducer entry}

Some of the organic acids which repressed $d$-tartrate dehydratase induction are structurally related to the inducer and it seemed possible that they inhibited by competing with the inducer for its entry-site into the cell. To test this possibility, the rate of $d$-tartrate metabolism of resting suspensions of organisms fully induced to $d$-tartrate was measured in the presence and absence of $d l$-malate and mesotartrate. $d$-Tartrate alone was utilized at a rate of $5.08 \mu \mathrm{mole} / \mathrm{hr} . / \mathrm{mg}$. dry weight of organisms, while in the presence of threefold greater concentrations of $d l$-malate or meso-tartrate the rates were 4.22 and $3.54 \mu \mathrm{mole} / \mathrm{hr} . / \mathrm{mg}$. dry weight respectively. These inhibitions (17-30\%) indicate that competition at the site of entry must be relatively slight. 


\section{Repression in pre-induced organisms}

Cohn \& Horibata (1959) reported that glucose completely repressed $\beta$-galactosidase induction in uninduced Escherichia coli, but that organisms actively forming $\beta$-galactosidase continued to do so at an unchanged rate for many generations in the presence of glucose plus inducer.

Effects of pre-induction were tested in Pseudomonas strain MD9 growing on $d$ - or $l$-tartrate. Cultures were transferred to medium containing the same isomer together with another organic acid in equimolar proportions. Transfers to fresh medium containing the same two substrates were made approximately every five generations to ensure the continued presence of high concentrations of unchanged substrates. After 15-23 generations, organisms were harvested and tested for ability to oxidize $d$ - or $l$-tartrate without lag. Pre-induction did not prevent repression of the $d$ - or $l$-tartrate oxidizing system by meso-tartrate or succinate (Table 5). Organisms grown on a mixture of $d$ - and $l$-tartrate were induced for the oxidation of both isomers, irrespective of the state of adaptation of the inoculum.

Table 5. Repression of tartrate dehydratase synthesis in pre-induced Pseudomonas strain MD9

\begin{tabular}{|c|c|c|c|c|c|c|}
\hline \multirow{2}{*}{$\begin{array}{c}\text { Growth } \\
\text { substrate } \\
\text { of } \\
\text { inoculum* }\end{array}$} & \multirow{2}{*}{$\begin{array}{c}\text { Substrates } \\
\text { in cultures } \\
\left(\text { each } 10^{-2} \mathrm{M}\right)\end{array}$} & \multirow{2}{*}{$\begin{array}{c}\text { No. of } \\
\text { generations } \\
\text { before } \\
\text { harvest }\end{array}$} & \multicolumn{4}{|c|}{$\begin{array}{c}\mathrm{O}_{2} \text { uptake on addition of substrate } 0-20 \mathrm{~min} \text {. } \\
(\mu \mathrm{l} . / \mathrm{mg} . \text { dry weight organism })\end{array}$} \\
\hline & & & $d$-tartrate & meso-tartrate & $l$-tartrate & $\underbrace{}_{\text {succinate }}$ \\
\hline$d$-tartrate & $\begin{array}{l}d \text {-tartrate }+ \\
\text { meso-tartrate }\end{array}$ & 20 & 4 & 113 & n.t. & n.t. \\
\hline$d$-tartrate & $\begin{array}{l}d \text {-tartrate }+ \\
\text { succinate }\end{array}$ & 23 & 3 & n.t. & n.t. & 86 \\
\hline$d$-tartrate & $\underset{l \text {-tartrate }}{d \text {-tartrate }}$ & 15 & 71 & n.t. & 60 & n.t. \\
\hline l-tartrate & $\begin{array}{l}\text { l-tartrate }+ \\
\text { meso-tartrate }\end{array}$ & 15 & n.t. & 78 & 6 & n.t. \\
\hline l-tartrate & $\begin{array}{c}\text { l-tartrate }+ \\
d \text {-tartrate }\end{array}$ & 15 & 68 & n.t. & $\mathbf{5 8}$ & n.t. \\
\hline
\end{tabular}

Table 6. Average generation times of Pseudomonas strains MD9, md and $\operatorname{lml}$ during growth on organic acids

$\begin{array}{ccccc}\begin{array}{c}\text { Pseudomonas } \\ \text { strain }\end{array} & \overbrace{\text { succinate }}^{\begin{array}{c}\text { meso-tartrate } \\ \text { generation time (min.) }\end{array}} & \text { pyruvate } \\ \text { MD9 } & \text { Substrate } & & \\ \text { MD } & 54 & 50 & 65 & 75 \\ \text { LML } & 58 & 53 & \mathbf{5 5} & 72 \\ & 59 & 59 & 65 & \mathbf{9 3}\end{array}$




\section{Correlation between growth rate in batch culture and repression}

Neidhardt \& Magasanik (1957) and Mandelstam (1962) showed that the degree of enzyme repression by various substrates tended to be related to the maximal growth rate supported by them. To determine whether a similar correlation exists in organisms which form tartrate dehydratases, the growth rate of three Pseudomonas strains in batch culture was compared (Table 7). In all cases growth was slower with pyruvate or $d$ - tartrate than with succinate or meso-tartrate, though with strain $\mathrm{lml}$ the difference was no greater than $10 \%$. These results are in keeping with those of the above mentioned authors, who found that carbon sources which supported a low growth rate repressed less effectively.

\section{DISCUSSION}

One of the aims of the present work was to compare the degree of repression of the three tartrate dehydratases in the same strain and under the same growth conditions and thus to evaluate the specificity of the inhibition. When repression occurred in any of the four strains examined, inhibition of the $d$ - and $l$-tartrate dehydratases was always much greater than inhibition of the meso-tartrate enzyme. This was most strikingly shown during growth on meso-tartrate itself, where the meso-tartrate dehydratase was formed at high rates while induction of the enzymes attacking $d$ - or $l$-tartrate was completely repressed. Similarly, Krebs cycle intermediates completely prevented induction by $d$ - or $l$-tartrate, while meso-tartrate induced formation of its dehydratase, although at a decreased rate. It may be noted that growth on meso-tartrate inhibited induction by the other two tartrate isomers, but did not prevent induction to gluconate oxidation.

The literature contains few reports of catabolite repression specific for particular enzymes. Neidhardt \& Magasanik (1957) described differential repression of histidase and inositol dehydrogenase in a strain of Aerobacter growing with glucose and histidine as sole nitrogen source. Both of these inducible enzymes were normally repressed by glucose, but under the above conditions histidase was formed while induction of inositol dehydrogenase remained inhibited. From these results the authors concluded that two different repressors acted on the synthesis of the enzymes (Magasanik, 1961). In the case of the tartrate dehydratases, however, differential repression could be equally well explained by different inhibitors or by a widely varying sensitivity to the same repressor.

Four of the seven substrates tested in the present work were effective repressors of induction by $d$ - or $l$-tartrate, while three (pyruvate, $d$-tartrate, $l$-tartrate) allowed induction to proceed at rates equivalent to those with inducer alone. It has been known for several years that some substrates repress enzyme induction much more strongly than others and Neidhardt (1960), Mandelstam (1961, 1962) and Magasanik (1961) have related these differences to differences in the relative rates of substrate metabolism and total cell synthesis. The compounds tested in the present work all enter cell metabolism via the Krebs cycle and at sites in the cycle close to each other. Thus, meso-tartrate and $l$-tartrate are both converted to oxaloacetate in a single enzymic step, and therefore give rise to identical metabolic intermediates, yet they have very different effects on induction by 
$d$-tartrate. It would appear therefore that the only metabolic differences which make for stronger or weaker repression are the rates of the first steps in substrate metabolism. Thus $d$ - and $l$-tartrate are ineffective as repressors because of relatively slow rates of conversion to oxaloacetate and pyruvate, due to relatively slow rates of entry or carboxylation to oxaloacetate. The suggestion that the initial steps of pyruvate, $d$-tartrate and $l$-tartrate metabolism are slower than those of the other compounds tested is in keeping with the somewhat slower growth rates supported by these three substrates. It is more directly supported by the finding that the amounts of $d$-tartrate dehydratase during growth on inducer alone were three to five times lower than those of meso-tartrate dehydratase. Such low amounts of $d$-tartrate dehydratase (and by analogy of $l$-tartrate dehydratase) during growth with inducer as sole carbon source may in fact be a corollary of the sensitivity of this enzyme to repression by its own catabolic products. Higher dehydratase concentrations would lead to repressor pools of the size formed during growth on meso-tartrate or Krebs cycle intermediates, and these would be accompanied by inhibition of enzyme synthesis and return to a low dehydratase content.

\section{REFERENCES}

Brown, D. D. \& Monod, J. (1961). Carbon source repression of $\beta$ galactosidase in Escherichia coli. Fed. Proc. $20,222$.

Cohn, M. \& Horibata, K. (1959). Physiology of the inhibition by glucose of the induced synthesis of the $\beta$ galactosidase enzyme system in Escherichia coli. J. Bact. 78, 624 .

Engelsberg, E., Watson, J. A. \& Hofre, P. A. (1961). The glucose effect and the relationship between glucose permease, acid phosphatase and glucose resistance. Cold. Spr. Harb. Symp. quant. Biol. 26, 261.

Friedman, T. E. \& Haugen, G. E. (1943). Pyruvic acid. II. The determination of keto acids in blood and urine. J. Hol. Chem. 147, 415.

Lowry, O. H., Rosebrough, N. J., Farr, A. L. \& Randall, A. J. (1951). Protein measurement with the Folin phenol reagent. J. biol. Chem. 193, 265.

MacQuillan, A. M. \& Halvorson, H. O. (1962). Metabolic control of $\beta$ galactosidase synthesis in yeasts. J. Bact. 84, 23.

Magasanik, B. (1961). Catabolite repression. Cold. Spr. Harb. Symp. quant. Biol. 26, 249.

Mandelstam, J. (1961) Induction and repression of $\beta$-galactosidase in non-growing Escherichia coli. Biochem. J. 79, 489.

Mandelstam, J. (1962). The repression of constitutive $\beta$-galactosidase in Escherichia coli by glucose and other carbon sources. Biochem. J. 82, 489.

Matchett, J. R., Legault, R. R., Nimmo, C. C. \& Notter, G. K. (1944). Tartrates from grape wastes. Industr. Engng Chem. (Industr.) 36, 851.

Monod, J. (1942). Recherches sur la croissance des cultures bactérienne. Paris: Hermann et Cie.

Neidhardt, F. C. \& Magasanik, B. (1957). Reversal of the glucose inhibition of histidase biosynthesis in Aerobacter aerogenes. J. Bact. 73, 253.

NeidHardr, F. C. (1960). Mutants of Aerobacter aerogenes lacking glucose repression. $J$. Bact. 80, 536.

REPASKE, R. (1958). Lysis of gram negative organisms and the role of versene. Biochim. biophys. Acta, 30, 225.

Rosenberger, R. F. \& Shilo, M. (1961). Diauxie in tartrate utilizing strains of Pseudomonas and its control by oxaloacetate. Biochem. biophys. Res. Comm. 4, 414.

ShrLo, M. (1957). The enzymic conversion of the tartaric acids to oxaloacetic acid. J. gen. Microbiol. 16, 472.

Shino, M. \& Stanier, R. Y. (1957). The utilization of the tartaric acids by Pseudomonas. J. gen. Microbiol. 16, 482. 